Vol. 122006 pp. 75-80

Jerzy Boryczka, Bohdan Mucha, Maria Stopa-Boryczka, Jolanta Wawer

Department of Climatology

E-mail: jkborycz@uw.edu.pl

\title{
THE INFLUENCE OF THE NORTH ATLANTIC OSCILLATIONS (NAO) ON THE CLIMATE OF WARSAW AND LVIV
}

\begin{abstract}
The objective of the work is to determine the periodicity and trends of change in air temperature in Warsaw and in Lviv during the $18^{\text {th }}-20^{\text {th }}$ centuries, together with the forecast for the years 2000-2100. There are interesting diagrams of temporal changes of the North Atlantic Oscillation (NAO) indicator and air temperature, with the forecast reaching the year 2100. The forecasts were obtained on the basis of interpretations of the Sun activity and the NAO indicator cycles, determined with the method of "regression sinusoids". The fluctuations of air temperature and North Atlantic Oscillation during winter in Warsaw and in Lviv are closely correlated.
\end{abstract}

Key words: air temperature, NAO, spectrum, periods, tendencies, Wolf number, forecast.

The dominating influence on the climate of Europe is exerted by two primary centres of the atmospheric pressure field: the Azores High and the Icelandic Low. These two pressure centres, associated with the difference of temperature between the waters of the North Atlantic and the continent, are negatively correlated with one another. This is the so-called North Atlantic Oscillation, NAO. In the situations of a high meridional pressure difference, that is - a significant gradient of pressure directed towards the North, air from above the Atlantic moves along the parallels from the West to the East - over the territory of Poland and Ukraine. The study refers to the NAO indicator, as defined by P. D. Jones et al. (1997), that is - the standardised pressure difference at sea level between Gibraltar and the South-West Iceland.

The strength of correlation between the winter air temperature in Warsaw, in Lviv and the NAO indicator is demonstrated by the comparison of their correlation coefficients (Table 1 ). 
Table 1.

Correlation coefficients between of air temperature in Warsaw, in Lviv and the North Atlantic Oscillation (NAO) in the years 1825-2000

\begin{tabular}{|l|c|c|l|c|c|}
\hline & Warsaw & Lviv & & Warsaw & Lviv \\
\hline$\underline{\text { January }}$ & $\underline{0.57}$ & $\underline{0.49}$ & July & 0.13 & 0.15 \\
$\underline{\text { Februarv }}$ & $\underline{0.55}$ & $\underline{0.44}$ & August & 0.08 & 0.16 \\
March & $\underline{0.49}$ & $\underline{0.40}$ & September & 0.27 & 0.22 \\
April & 0.12 & 0.12 & October & 0.25 & 0.05 \\
May & 0.13 & -0.02 & November & 0.38 & 0.20 \\
June & 0.13 & 0.05 & December & 0.41 & 0.33 \\
\hline
\end{tabular}

The changes of air temperature in Warsaw, Lviv and the North Atlantic Oscillation are shown in Fig. 1.

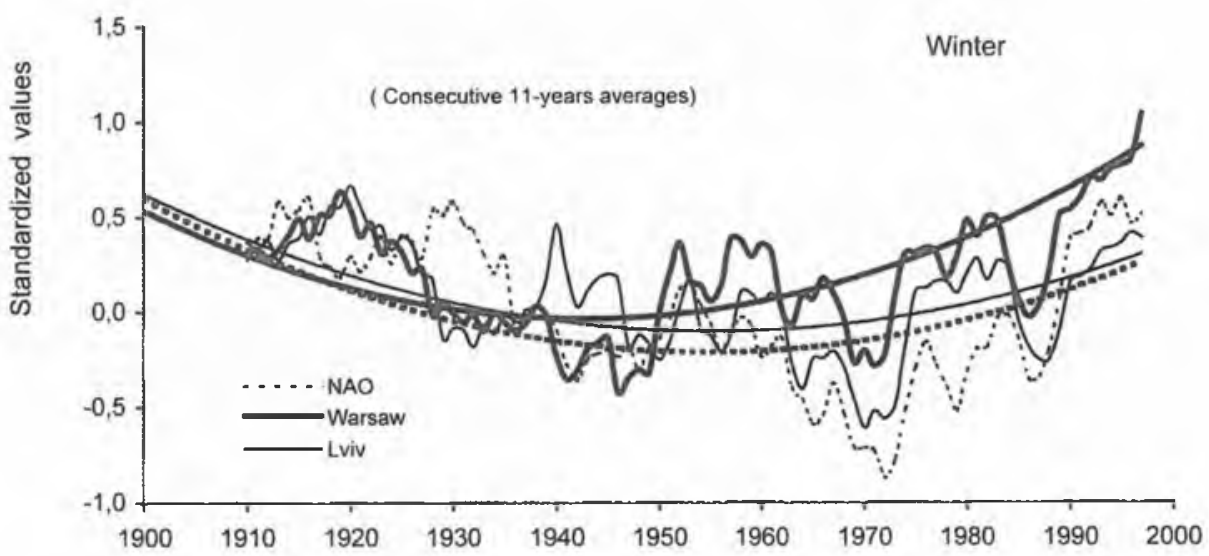

Fig. 1. Changes of air temperature in Warsaw, Lviv, and NAO indicator in the years 1900-2000

The tendencies in the air temperature and NAO in the years 1900-2000 are defined by the regression equations $\left(T=A_{0}+A_{1} t+A_{2} t^{2}, A=\partial T / \partial t=\right.$ $A_{1}+2 A_{2} t, t$ - time):

$T_{w}=0.00030897 t^{2}-1.2006 t+1166.2 . t_{\min }=1942$

$T_{L}=0.00023464 t^{2}-0.9177 t+897.15 . t_{\min }=1956$

$N A O=0.00026727 t^{2}-1.045 t+1021.3 . t_{\min }=1955$

In general, air temperature in Warsaw and Lviv tended to decrease in the years 1900-1942, 1900-1956 $(A<0)$ and increased in the years 1943-2000, 1957-2000 $(A>0)$.

The North Atlantic Oscillation tended to decrease in the years 1900-1955 and increased, in the years 1956-2000 $(A>0)$.

The NAO indicator, in the winter, in years $1825-2000$, is characterised by periodicity with the cycle equal to around 8 and 100 years, i.e.: $7.8,105.2$ years. It is interesting to compare the spectra: air temperature during winters in Warsaw, and in Lviv in the years 1900-2000. The spectra are 
characterised by a similar periodicity. with the dominant period of about 7.8 years. The similarity between the two spectra indicates that winters in Warsaw are shaped by periodic fluctuations of the NAO index (zonal circulation).

Their presence in almost all of the chronological series (of the monthly and seasonal values) confirms the fact that this periodicity characterises the temperature field in Europe. The periods of the NAO indicator in winter are dominated similarly as the periods of air temperature in Warsaw (8.3, 98.5 years) and Lviv (8.3, 19.3, 109.9 years) .

The spectra and the cycles of air temperature (Fig.2-3) and the NAO indicator were determined the method of "regression sinusoids" (Boryczka, 1998): the method consists of adjusting the results of the $y_{1}, \ldots, y_{\mathrm{n}}$ measurements performed in time $t_{1}, \ldots, t_{\mathrm{n}}$ (using the smallest square values) of consecutive sinusoids with presumed cycles, e.g. $\Theta=1,2, \ldots, n$ (or 0.1 ; $0.2 ; \ldots ; n)$. the regression sinusoid equation (as referred by the author) with the cycle $\Theta$. amplitude $b$ and phase $c$ :

$$
y=a+b \sin (\omega t+c) . \quad \omega=2 \pi / \Theta
$$

The spectrum is a sequence of values of residual variance $\varepsilon^{2}$, corresponding to the presumed cycles $\Theta=0.1 ; 0.2 ; \ldots ; n$. The cycles denote the local minimums $\Theta_{\min }$ of the residual variance $\varepsilon_{\text {min. }}^{2}$

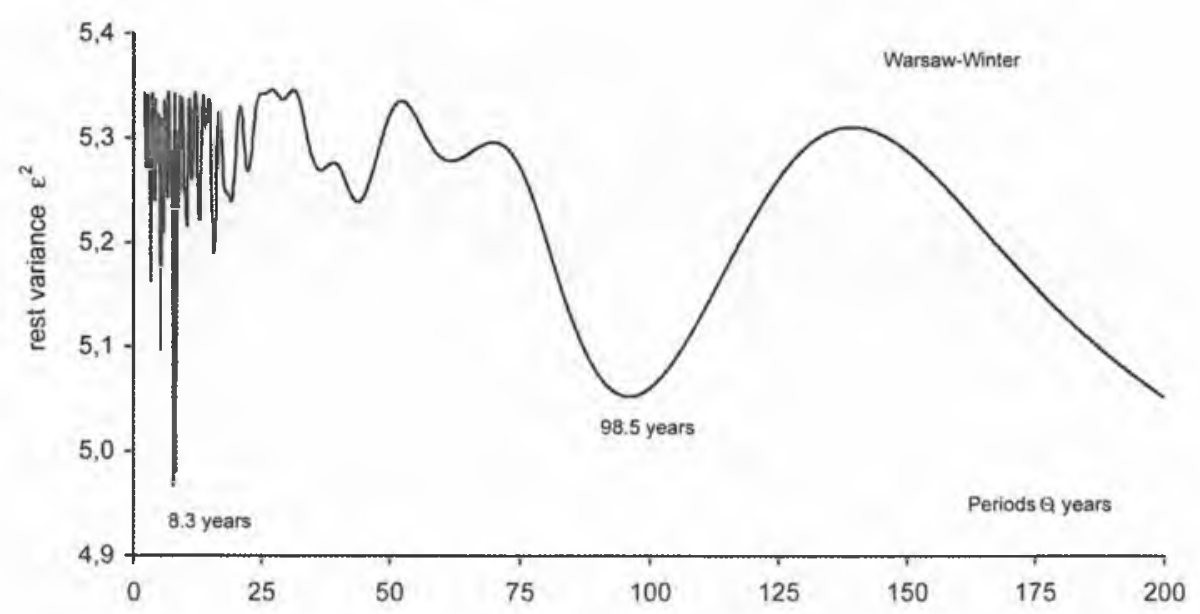

Fig.2. The spectrum of air temperature in Warsaw in the years 1779-2000 (in the strip 2.0-200 years, $\Delta \Theta=0.1$ ) - winter

The changes of air temperature in winter in Warsaw and Lviv are shown in Fig. 4. In the measurement intervals these are the values of the function approximating the function $T=f(t)$. while outside these intervals prediction values are given. Tendencies in air temperature are defined by the linear regression equations $T=A_{0}+A t$ ( Warsaw $-A=1.1^{\circ} \mathrm{C} / 100$ years, 


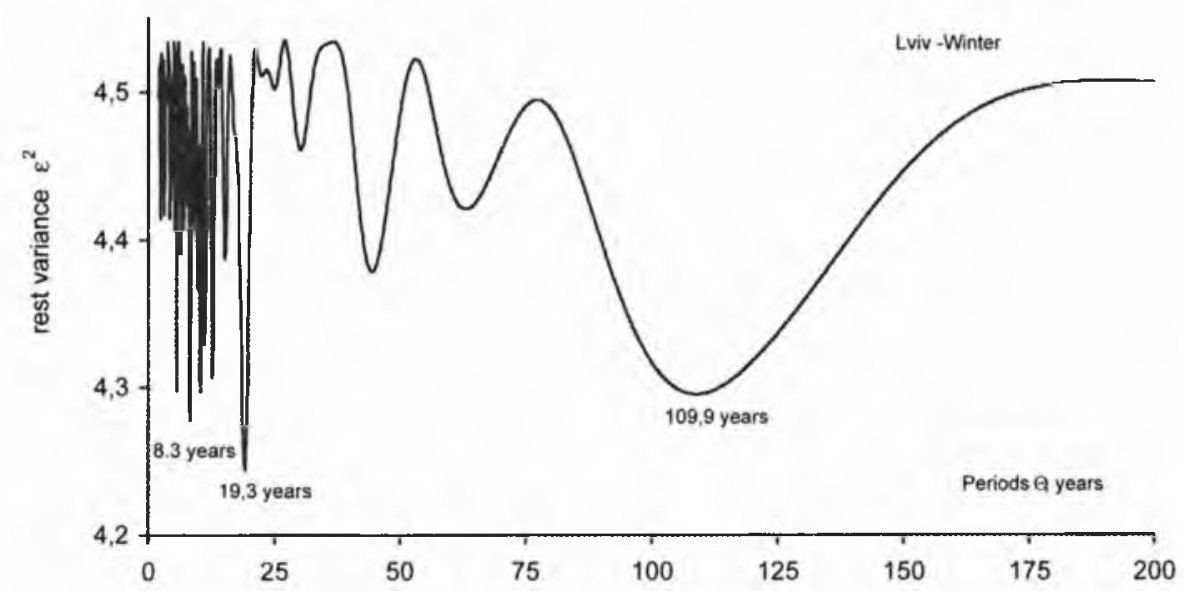

Fig. 3 The spectrum of air temperature in Lviv in the years 1824.2002 (in the strip 2.0.200 years, $\Delta \Theta=0.1$ ) - winter

Lviv $-A=0.7^{\circ} \mathrm{C} / 100$ years). The coefficients are usually positive $(A>0$, increasing tendencies).

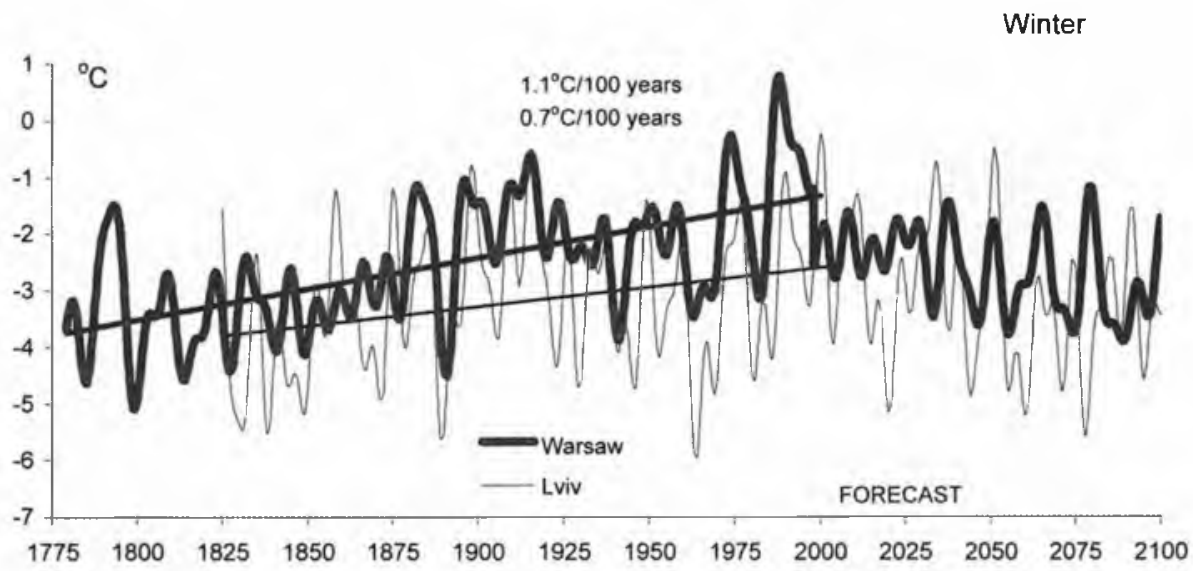

Fig. 4. The changes of air temperature in Warsaw in the years 1779-2100, and in Lviv in the years 1824-2100, the forecast for $21^{\text {st }}$ century (winter)

The forecast of air temperature in Warsaw, and Lviv were obtained on the basis of interference of the cycles:

$$
T=f(t)=a_{\mathrm{o}}+\Sigma_{\mathrm{j}} b_{\mathrm{j}} \sin \left(2 \Pi t / \Theta_{\mathrm{j}}+c_{\mathrm{j}}\right) .
$$

where: $\Theta_{j}$ - periods, $b_{j}$ - amplitudes, $c_{j}$ - phase

The coldest winters in Warsaw and in Lviv will occur most likely in the middle of this century, around the year 2050 . They will be slightly milder 
than those in the beginning of the $19^{\text {th }}$ century because of the gradually larger contribution of the anthropogenic factors.

The progressive warming of Earth's climate is mainly caused by natural factors, that is increasing solar activity. The aspects which testify to the predominance of natural factors include synchronous changes in the average air temperature in Europe: Paris, Berlin, Stockholm, Warsaw, Cracow, Prague,Vienna, Tallinn, Basle, Oxford in the years 1856-2000 (Fig.5). the average consecutive 11-year Wolf numbers (Fig.6).

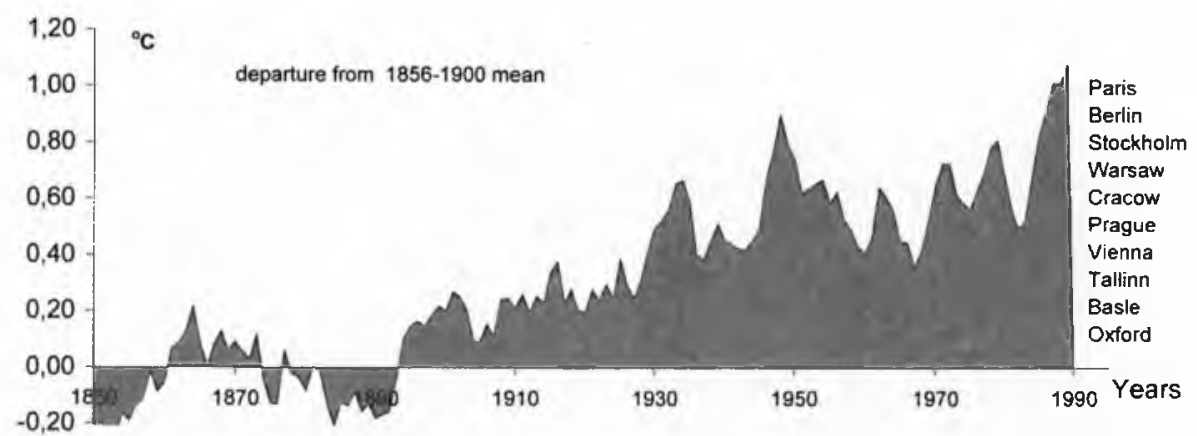

Fig. 5. Changes of air temperature in Europe (Paris, Berlin, Stockholm, Warsaw, Cracow, Prague,Vienna, Tallinn, Basle) in the years $1856-2000$ (deviations from the average value for the years 1856-1900)

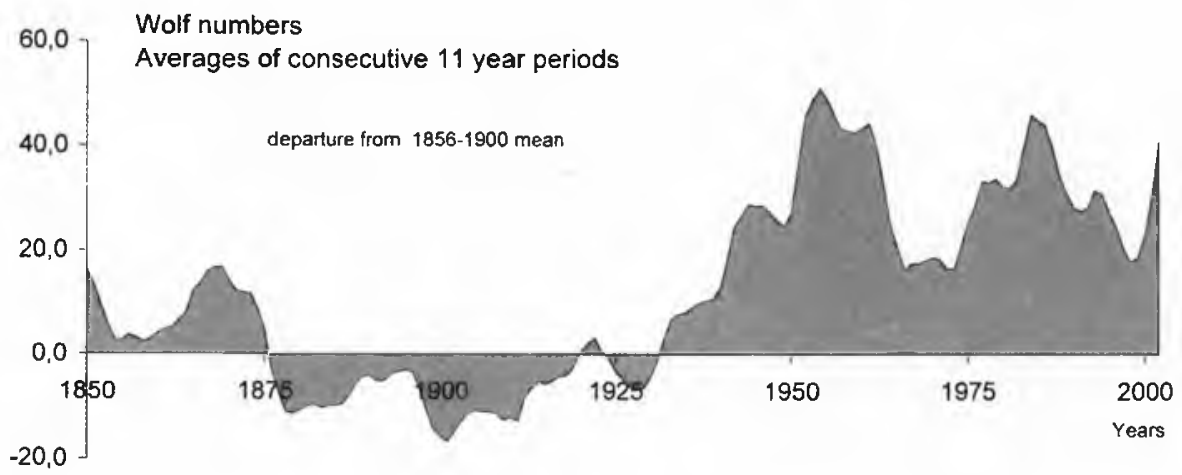

Fig. 6. Changes in solar activity (Wolf numbers) in the years 1856-2002 (deviations from the average value for the years 1856-1900)

Synchronous changes in the average air temperature in Europe in the years 1856-2000 and the average consecutive 11-years cycle of the Wolf numbers testify to the significant role that the solar activity plays in shaping of the Earth's climate. 
Deviations from the average air temperature in Europe in the years 1856-1900 are, as a rule, negative prior to 1920 and positive, after 1920. The years 1920-2000 are characterised by a significant warming with the local minimum in the 1960s. The situation is similar in the case of average consecutive deviations relating to the Wolf numbers for 11-year cycles from the average value for 1856-1900. They are negative until 1925 and positive after 1925. The main local minimum of the temperature in the 1960s. is matched by the main local minimum for the Wolf numbers; the solar activity in 1925-2002 is also significantly greater than before 1925 .

\section{REFERENCES}

Bernes C., 2003, A Warmer World. The Greenhouse Effect and Climate Change. monitor 18. Swedish Environmental Protection Agency, SWE CLIM.

Boryczka J., 2003, Trends in Climate Change in Europe and Their Causes, [in:] Man and Climate in the $20^{\text {th }}$ Century (ed. J. L. Pyka et al.). Studia Geograficzne 75 . Wyd. Uniwersytetu Wrocławskiego, Wroclaw.

Boryczka J., Stopa-Boryczka M., Baranowski B., Kirschenstein M., Błażek E., Skrzy pczuk J., 2003, Atlas wspótzależności parametrów meteorologicznych $i$ geograficznych $w$ Polsce [Atlas of the Interrelationships of the Meteorological and Geographical Parameters in Poland; in Polish]. v. XVII. Mroźne zimy i upalne lata w Polsce [Very Cold Winters and Very Hot Summers in Poland; in Polish], Wyd. UW, Warszawa.

Petit J. R., Jouzel J., Ray naud D. et al., 1999. Climate and Atmospheric History of the Past 420000 Years from the Vostok Ice Core. Antarctica, Nature 399, p. 429.

English translation: Bohdan Mucha 